\title{
Desplazamiento forzado y Consejo de Estado. Un juez amplio considerando pero tímido fallando
}

\author{
Forced Displacement and State Council. The Judge who Had \\ a Wide Range of Arguments but not a Broad Extent of Decisions \\ Deslocamento forçado e Conselho de Estado. Um juiz amplo \\ considerando, mas tímido sentenciando
}

\author{
Miguel ANDRÉS LÓPEZ MARTíNEZ* \\ Universidad Santo Tomás
}

FECHA DE RECEPCIÓN: 14 DE ENERO DE 2014 • FECHA DE ACEPTACIÓN: 8 DE ABRIL DE 2014

Doi: dx.doi.org/10.12804/esj 16.02.2014.04

Para citar este artículo: López M., M. A. (2014). Desplazamiento forzado y Consejo de Estado. Un juez amplio considerando pero tímido fallando. Estudios Socio-Jurídicos, 16(2), 127-162. Doi: dx.doi.org/10.12804/esj 16.02.2014.04

\section{RESUMEN}

La reparación a las víctimas del desplazamiento forzado es uno de los retos más importantes de nuestra sociedad, que se puede lograr a través de la declaratoria de la responsabilidad estatal. Ante un fenómeno tan complejo, la intervención del juez acarrea algunas dificultades que podrían superarse si se ajustaran sus conceptos y prácticas a la luz de las recomendaciones hechas por expertos. La Sentencia T-025 de 2004 y su posterior seguimiento inspiraron a muchos de estos para proponer soluciones al estado de cosas inconstitucional (ECI) evidenciado por la Corte Constitucional. Nos interesó saber cuáles propuestas lograron permear el campo de la responsabilidad patrimonial del Estado, para luego averiguar qué tan sensible fue el juez de lo contencioso-administrativo a las preocupaciones de los académicos. En el primer sentido, identificamos 18 propuestas bajo el rótulo de líneas de fuga teórica, como alternativas planteadas para ampliar el alcance del daño, su imputación y reparación en el ámbito de reclamación judicial. En el segundo sentido, contrastamos dichas líneas con los argumentos de cuatro fallos proferidos por el Consejo de Estado en esta materia entre 2004 y 2010. Finalmente, pudimos evidenciar que las líneas de fuga teórica no influyeron profundamente en la actividad del juez: aunque sus consideraciones fueron amplias al valorar

* Magíster en Derecho Administrativo del Colegio Mayor de Nuestra Señora del Rosario; abogado de la Universidad Santo Tomás Tunja. Docente investigador de la Universidad Santo Tomás Tunja. Correos electrónicos: maloma11@hotmail.com, maloma11ster@gmail.com. Dirección: calle 25 \# 6B-27 (Tunja, Colombia). 
el desplazamiento como un evento dañino complejo, sus órdenes se dieron dentro de los parámetros tradicionales.

Palabras clave: desplazamiento forzado, Consejo de Estado, responsabilidad patrimonial del Estado por desplazamiento forzado, líneas de fuga teórica.

\section{ABSTRACT}

People in forced displacement can receive reparations through the State liability declarations by a judge. Judgment could involve some disadvantages but it is still probably to overcome them if the judge attends experts' recommendations. Theorists were inspired in unconstitutional statu quo showed by Constitutional Court in T-025 case in 2004. We attempt to identify the proposals that influenced the State liability area and specifically the way in which they changed the frame of administrative judge's decisions. First, we identified 18 theoretical scape lines, as alternatives to understand in a wider sense the damage, its imputation and reparation in a judicial landscape. Second, we attempt to establish if the State Council was influenced by the theorists' suggestions, by studying four decisions published from 2004 until 2010. The evidence has shown that the administrative judge was far from the theorists' proposals, although his attempts to offer better conditions to the victims.

Key words: forced displacement, State Council, State liability because of forced displacement, theoretical scape lines.

\section{RESUMO}

A reparação às vítimas do deslocamento forçado é um dos retos mais importantes de nossa sociedade que se pode conseguir através da declaratória da responsabilidade estatal. Ante um fenômeno tão complexo, a intervenção do juiz acarreta algumas dificuldades que poderiam ser superadas se se ajustaram seus conceitos e práticas à luz das recomendações feitas por expertos. A sentença T-025 de 2004 e seu posterior seguimento inspiraram a muitos deles a propor soluções ao Estado de coisas inconstitucional (ECI) evidenciado pela Corte Constitucional. Interessou-nos saber quais propostas lograram permear o campo da responsabilidade patrimonial do Estado, para depois averiguar que tão sensível foi o juiz do inquérito administrativo às preocupações dos acadêmicos. No primeiro sentido, identificamos 18 propostas sob o rótulo de linhas de fuga teórica, como alternativas expostas para ampliar o alcance do dano, sua imputação e reparação no âmbito de reclamação judicial. No segundo sentido, contrastamos ditas linhas com os argumentos de quatro sentenças proferidas pelo Conselho de Estado nesta matéria entre 2004 e 2010. Finalmente, pudemos evidenciar que as linhas de fuga teórica não influíram profundamente na atividade do juiz: ainda que suas considerações foram amplas ao valorizar o deslocamento como um evento daninho complexo, suas ordens se deram dentro dos parâmetros tradicionais.

Palavras-chave: Deslocamento forçado, Conselho de Estado, responsabilidade patrimonial do Estado por deslocamento forçado, linhas de fuga teórica. 


\section{Introducción}

El conflicto armado ha dejado una huella de sangre y miseria imborrable en nuestro pasado y presente. El desplazamiento forzado (DEFO) es una de sus manifestaciones y sus víctimas son las más lastimadas por los actores armados, las autoridades y la sociedad. Repararlas es uno de los principales retos del Estado y la sociedad colombiana. Ignorarlo implicaría prolongar esa huella hacia el futuro.

La reparación de las víctimas del desplazamiento se puede garantizar a través de dos mecanismos: el legal-administrativo y el judicial. En el primer caso, los remedios al daño se conceden a los perjudicados que cumplen algunos requerimientos contenidos en la ley o en otras normas, de acuerdo con tarifas previamente establecidas y sin que sea necesario identificar al autor material. En el segundo, las víctimas reciben reparación cuando la reclaman ante un juez, cumplen las etapas de un proceso y triunfan en un debate probatorio en el que se logra identificar al responsable de los perjuicios.

Ambos ofrecen ventajas y desventajas. La reparación por vía administrativa permite reparar en contextos en los que no es posible identificar la plena magnitud del daño y sus responsables, de manera que implica menores cargas probatorias para las víctimas. Además, ofrece mayor cobertura y facilita el aprovechamiento eficiente de los recursos con la entrega de paquetes uniformes de beneficios. A todo lo anterior, debe sumarse que los remedios pueden llegar más pronto y ser más oportunos que los ofrecidos después de un largo proceso judicial. Sin embargo, se puede ignorar que el DEFO causa impactos diferentes en sus víctimas al reparar bajo un sistema de tarifas. Así mismo, al no hacer mucho énfasis en la identificación de los responsables, pueden quedar abiertas las puertas hacia la impunidad y la violación de los derechos a la verdad y la justicia (Uprimny, Sánchez y Bolívar, 2010, pp. 2-17).

La reparación judicial es un mecanismo que permite el acceso a mayores beneficios debido a la búsqueda de la reparación integral. Al revisar casos concretos, permite pensar en medidas más adecuadas para atenuar el daño de las víctimas más vulnerables. Además, las sentencias ofrecen mandatos directos que tienen la virtud de formar precedente y generar mayor compromiso de las autoridades. No obstante, una de las desven- 
tajas de este mecanismo es que en términos reales solo algunas víctimas acceden al juez (De Greiff, 2006). Las razones son muy variadas, desde el desconocimiento de las normas hasta el temor de volver a ser perseguido. En una tragedia como el DEFO, la reunión de pruebas es casi imposible y los tiempos del juez son muy prolongados. A la excesiva demora para proferir un fallo, debemos sumarle la alta probabilidad de que se torne insostenible la reparación a largo plazo: al reconocer beneficios para una víctima demandante, las autoridades pueden quedarse sin recursos para atender a quienes no demandaron (Uprimny, Sánchez y Bolívar, 2010, pp. 14-21; PNUD, 2011, pp. 119-135).

¿Podríamos lograr algún mecanismo de reparación que beneficiara a las víctimas con las ventajas de los dos anteriores sin que las atara a sus desventajas? Es imposible prescindir de alguno de estos porque se trata de canales necesarios y complementarios. Las debilidades del sistema legaladministrativo pueden superarse a través de las fortalezas del judicial y viceversa (Uprimny y Sánchez, 2010; Ghersi, 2013). En esta oportunidad, nos interesa revisar cómo pudo haberse ajustado el mecanismo judicial, entre los años 2004 y 2010, para que ofreciera las mejores respuestas a la población en situación de desplazamiento (PSD), no solo en términos de reparación, sino también de mejores herramientas conceptuales frente al daño y su imputación.

Dentro de los escenarios de reparación nos interesa el judicial, en concreto el de la responsabilidad patrimonial del Estado (REPE). Tenemos razones de orden teórico y práctico para explicarlo. La primera de ellas es que por esta vía se puede ofrecer a las víctimas un remedio a sus daños, pero también una declaratoria de responsabilidad de las autoridades que tuvieron que ver con su ocurrencia. El juez controla así la conducta del Estado y genera mayor compromiso en la prevención de daños futuros. La responsabilidad permite ejercer control social. Como se sabe, las autoridades tienen una serie de funciones asignadas con el fin de que contribuyan a realizar los fines estatales. La institución permite revisar si dichas actividades se desarrollan conforme a los objetivos señalados o constituyen, por el contrario, fuentes de daños a los ciudadanos (Mir, 2002, pp. 110-130; Saavedra, 2005, p. 197; Rebollo, 2007).

La segunda radica en el hecho de que la reparación por declaración de la REPE es una fuente potencial de mayores beneficios para las víctimas. 
De acuerdo con los cálculos de la Comisión de Seguimiento a la Política Pública sobre Desplazamiento Forzado, los montos estimados para reparar el daño de 5.373 .265 víctimas son (en cifras del año 2011) 145,7 billones si se siguen los estándares ofrecidos por la jurisprudencia de la Corte Interamericana de Derechos Humanos; 26,9 billones, bajo las líneas de la reparación legal-administrativa (contenidas en el Decreto 1290 de 2008); 164,2 billones si se tienen en cuenta los argumentos señalados en la jurisprudencia del Consejo de Estado (Comisión de Seguimiento a la Política Pública sobre Desplazamiento Forzado, 2011, pp. 124-141).

Finalmente, la Corte Constitucional (CC) ha sido enfática al afirmar la importancia y la necesidad de complementar el mecanismo de reparación legal-administrativa con el judicial. En el debate suscitado en torno al artículo 132 de la Ley 1448 de 2011, que anteponía un contrato de transacción como obstáculo para llegar a los estrados judiciales cuando se recibía una indemnización, la Corte condicionó la constitucionalidad de la norma bajo una interpretación que respetó los alcances de la REPE: es posible que las víctimas reclamen reparación ante el juez cuando sufran daños antijurídicos provenientes de crímenes de lesa humanidad atribuibles al Estado (además de recibir indemnización administrativa). De lo contrario, precaver litigios a través de la transacción implicaría admitir la impunidad y contrariar los fines de pacificación que persigue la ley (CC, SC-099/13, fundamento 6.2).

Nos interesa revisar el canal judicial que conduce a la reparación de las víctimas del DEFO y a la declaratoria de responsabilidad estatal; también saber cómo podría ajustarse para que sus debilidades no sean prominentes. Creemos que en este contexto los conceptos, argumentos y prácticas tradicionales de la REPE se quedan cortos ante una tragedia tan compleja y arraigada en nuestra historia. Por ello, nos concentraremos además en las principales preocupaciones de los académicos en torno a las condiciones de reclamación judicial de reparación de la PSD, inspiradas en la declaratoria del estado de cosas inconstitucional (ECI) en 2004. Trataremos de hacer un recorrido breve de las observaciones que nos llevaron a esta última inquietud.

La reparación de las víctimas del DEFO fue un punto pendiente en las primeras agendas de las autoridades públicas. La Ley 387 de 1997 y sus decretos reglamentarios aportaron pocos elementos para garantizarlo. Los primeros intentos por atender las necesidades de la PSD se dieron alrededor de otros derechos, como la asistencia humanitaria y el retorno. Con la 
Sentencia T-025 de 2004, la Corte Constitucional evidenció una violación masiva de los derechos de la PSD debido a la descoordinación institucional que soportaban para acceder a los beneficios de la Ley 387 y a la falta de recursos económicos destinados a atenderla. ${ }^{1}$ Por ello, declaró el ECI y profirió órdenes generales de ajuste a la política pública. La reparación se concibió como parte de la carta de los derechos de la PSD y fue objeto de ajustes de política pública durante el proceso de seguimiento (ST-025/04, fundamento 10.1).

En el Auto 8 de 2009, la Corte evidenció que las autoridades habían hecho esfuerzos incipientes para garantizar los derechos a la justicia, verdad y reparación de la PSD. Constató que en materia de reparación subsistían grandes obstáculos procedimentales e institucionales sin una solución a la vista. Los decretos de indemnización administrativa, por ejemplo, se diseñaron sin la participación de las víctimas, sin tener en cuenta las dimensiones reales del daño, excluyendo a quienes fueron perjudicados por agentes del Estado, bajo la confusión de los conceptos de reparación y política pública social (A-8/09, fundamentos 97-107).

Para corregir tales obstáculos, se impuso la orden de formular e implementar medidas de reparación con enfoque de derechos humanos. La orden no fue plenamente cumplida. En el Auto 219 de 2011, la Corte encontró que las acciones emprendidas por las autoridades fueron insuficientes para reparar a las víctimas. Además, observó que, a pesar de la formulación de indicadores y del nuevo diseño institucional que proyectó la Ley 1448 de 2011, no se evidenciaron avances reales en los procesos de investigación, juzgamiento y sanción de los responsables del DEFO, ni de reparación integral a las víctimas (A-219/11, fundamentos 125-157).

A pesar del corto alcance de la declaratoria del ECI para garantizar la reparación a la PSD, el fallo y su posterior seguimiento dejaron una marca simbólica importante en la sociedad: abrieron un espacio para el diálogo entre instituciones, víctimas y académicos, lo que permitió mejorar nues-

1 Por una parte, la cantidad de recursos destinada para financiar la atención de la PSD fue insuficiente: mientras que en el año 2002 se destinaron 103.491 millones de pesos, en 2003 el dígito se redujo a 70.783 millones (fundamento 6.3.2.). Por otra parte, la incapacidad institucional se reflejó en fallas en el diseño (planes sin indicadores ni metas, asignación difusa de responsabilidades), implementación (aplicación de herramientas insuficientes en términos de tiempo y cobertura), seguimiento y evaluación de la política pública (subregistro de PSD y sistemas de información incompletos) (fundamento 6.3.1). 
tras explicaciones del fenómeno. El efecto del fallo fue doble: por un lado, puso de moda el tema del DEFO en las agendas de política pública; por el otro, dio audiencia a otras voces en la sociedad civil con fortalezas jurídicas para enriquecer el debate y la búsqueda de soluciones. César Rodríguez y Diana Rodríguez (2010, pp. 172-188) denominaron esta clase de impacto simbólico efecto deliberativo. Con este rótulo, indicaron la relevancia de la sentencia para poner a dialogar a la sociedad con sus autoridades (activismo dialógico) y transformar nuestra idea del desplazamiento y de sus víctimas. Sin embargo, advierten que los protagonistas de la discusión han elevado el debate a niveles tan especializados que a veces deja de ser claro para la PSD.

La declaratoria del ECI en 2004 funcionó como el detonante de una explosión de propuestas académicas. Nos interesó saber cuáles lograron permear el campo de la REPE, para luego averiguar qué tan sensible fue el juez de lo contencioso-administrativo a las preocupaciones de los académicos. Creemos que de esta manera se pueden hallar algunas pistas sobre cómo ajustar el canal judicial, concretamente el de la REPE, que conduce a la reparación de las víctimas del DEFO.

En este orden de ideas, el presente escrito retrata una aventura mental en busca de respuestas a un interrogante central: ¿El Consejo de Estado tuvo en cuenta las propuestas (preocupaciones) que formularon los teóricos para mejorar las condiciones de las víctimas en la reclamación judicial de reparación a la hora de definir la responsabilidad de las autoridades por desplazamiento forzado, entre 2004 y 2010?

Pero para darle respuesta tendremos que dilucidar primero dos inquietudes:

¿Cuáles fueron los principales argumentos del Consejo de Estado a la hora de declarar la responsabilidad patrimonial del Estado por el desplazamiento forzado de ciudadanos, entre 2004 y 2010 ?

¿Cuáles fueron las principales preocupaciones de los académicos frente a las condiciones de reclamación judicial de reparación de las víctimas del DEFO, inspiradas en la declaratoria del ECI en 2004? 


\section{Metodología}

Para llegar a la respuesta a cada una de las preguntas, debimos recorrer caminos distintos. En cuanto al primero, hicimos una selección y lectura detallada de cuatro fallos representativos del Consejo de Estado. Tuvimos en cuenta tres criterios: material, procedimental y temporal. El primero, relacionado con el contenido de los fallos; el segundo, con la naturaleza del proceso que se resolvía en las sentencias; y el tercero, con la época en que fueron proferidos.

De acuerdo con el criterio material, seleccionamos aquellos en los que el juez definió la responsabilidad estatal por el desplazamiento forzado y masivo de ciudadanos, es decir, de un conjunto de diez o más hogares (equivalente al de 50 personas) (D. 2569/00, art. 12). La idea era encontrar sentencias que evidenciaran el estudio de todos los elementos de la REPE: daño antijurídico, imputación y reparación. Según el procedimental, estudiamos aquellos proferidos en desarrollo de acciones de grupo y reparación directa ( 3 y 1, respectivamente) porque nos permitían una aproximación más detallada a los obstáculos formales que enfrentaron las víctimas. Finalmente, el criterio temporal nos llevó a pensar en decisiones tomadas entre los años 2004 y 2010. Creemos que dentro de este período los académicos recibieron una poderosa influencia de la Sentencia T-025 y, por ello, el juez contencioso pudo haber sido alcanzado por sus ideas, difíciles de percibir antes, pero, sobre todo, después de la Ley 1448, pues esta última amplió directamente el panorama judicial de reparación a las víctimas del conflicto.

Para llegar a la segunda respuesta, rastreamos las propuestas lanzadas por académicos reconocidos como soluciones al problema de la reparación de las víctimas del DEFO. Las identificamos con el rótulo de líneas de fuga teórica porque se trata de intentos de brindar mejores explicaciones y soluciones, inspirados en una visión interdisciplinar del problema del desplazamiento. La expresión obedece a la preocupación de Ana Carolina Ramírez (2010), para quien el mapa teórico sobre desplazamiento forzado se saturó de propuestas repetitivas. A su juicio, es necesario encontrar líneas que aporten soluciones adecuadas e ingeniosas sin que se aparten de la realidad del fenómeno.

Para la búsqueda y selección de estas líneas de fuga, tuvimos en cuenta aquellos textos que mostraran una relación entre la reparación de las víctimas 
por vía judicial y el ECI por DEFO, publicados entre los años 2004 a 2010. Encontramos dos tipos de preocupaciones: conceptuales y procedimentales. Las primeras están relacionadas con la estructura de conceptos, creencias y valores inmersos en la reparación judicial; las segundas, con los trámites del procedimiento que debían cumplir las víctimas para obtenerla. Algunas son más explícitas que otras, por eso, en algunos casos, nos atrevimos a perfilar sus contenidos. Además, decidimos presentarlas teniendo en cuenta su relación con los conceptos centrales de la REPE: daño, imputación y reparación.

El camino hacia la tercera respuesta comenzó en un ejercicio de contraste entre las líneas de fuga teórica y el contenido de los fallos seleccionados. Decidimos plasmarlo en términos numéricos para hacer más evidente la relación. Por esto, diseñamos dos instrumentos de análisis: la escala de fuga teórica y el índice de fuga teórica. A través de la primera, evidenciamos el impacto que tuvo cada propuesta académica sobre los argumentos y órdenes del juez. Por medio del segundo, establecimos qué tan cerca o lejos estuvo cada fallo de lograr una solución ideal a las víctimas que reclamaron reparación. Los detalles de cada herramienta se darán en el acápite de resultados.

\section{Resultados}

Cada uno de los caminos que señalamos atrás nos llevó a una serie de resultados que presentaremos en tres partes. Una primera relacionada con el contenido de los fallos estudiados; la segunda, con las líneas de fuga teórica identificadas; y la tercera, con el ejercicio de contraste entre argumentos judiciales y propuestas teóricas.

\subsection{Argumentos del Consejo de Estado al declarar la responsabilidad patrimonial del Estado por el desplazamiento forzado entre 2004 y 2010}

Seleccionamos cuatro fallos con antecedentes fácticos similares: desplazamiento forzado masivo perpetrado por grupos paramilitares en zonas álgidas de la geografía del conflicto. En todos los casos, las amenazas de grupos paramilitares hacia la población civil motivaron los desplazamientos como una estrategia de supervivencia. En algunos fueron la respuesta 
a masacres (La Gabarra, Alto Naya) y retenes (La Gabarra, Filogringo), en las que se buscaba exterminar a colaboradores de la guerrilla. ${ }^{2}$

Los éxodos emprendidos por la población civil constituyeron medidas preventivas ante reiteradas amenazas que fueron conocidas por ONG, autoridades gubernamentales, la Policía y las Fuerzas Militares. En todos los fallos que comentaremos, las precarias condiciones de seguridad hicieron imposible el retorno, por lo que la gravedad de los perjuicios y del desarraigo es un aspecto marcado y común.

\subsubsection{En cuanto al daño antijurídico indemnizable}

En cuanto a la definición del daño antijurídico indemnizable, el Consejo de Estado consideró el desplazamiento como un fenómeno que dejó en sus víctimas secuelas de orden patrimonial y extrapatrimonial. Dentro de las primeras, fueron representativas las pérdidas de bienes raíces y de ingresos. Dentro de las segundas, las afectaciones morales y de las condiciones de existencia.

La principal afectación económica identificada fue la destrucción de vivienda y el despojo de los bienes inmuebles que poseían las víctimas antes del éxodo. En ningún momento fueron consideradas hechos notorios (como sí ocurrió con el daño moral) y su prueba estuvo señalada por los informes de peritos o comisiones especiales de investigadores. También se tuvieron en cuenta los subsidios administrativos para solución de vivienda, como indicios de pérdida de bienes.

En cuanto a la pérdida de muebles o enseres, por una parte, el juez fue muy estricto al exigir su prueba. Ante la dificultad para allegarla, solo fue posible en el caso Filogringo (2007), en donde los registros de las ONG hicieron posible evidenciarla. Sobre el perjuicio lucro cesante, poco se dijo. Aunque el juez reconoció la magnitud de la tragedia humanitaria, no tuvo

2 Los fallos estudiados fueron proferidos por el Consejo de Estado, Sala de lo Contencioso Administrativo, Sección Tercera: sentencia del 26 de enero de 2006, Radicación 25000-23-26 000-2001-00213-01 (AG), C. P. Ruth Stella Correa, actor: Jesús Emmel Jaime Vaca y otros (caso La Gabarra, 2006); sentencia del 15 de agosto de 2007, Radicación 190012331000200300385-01, C. P. Mauricio Fajardo, actor: Antonio María Ordóñez Sandoval y otros (caso Alto Naya, 2007) sentencia del 15 de agosto de 2007, Radicación 25000-23-27-000-2002-00004-01 (AG), C. P. Ruth Stella Correa Palacio, actor: Yudy Esther Cáceres y otros (caso Filogringo, 2007); y sentencia del 18 de febrero de 2010, Expediente 18.436 (reparación directa), C. P. Mauricio Fajardo, actor: Manuel Narváez Corrales y otros (caso Bellacruz, 2010). 
los mismos alcances para hacer lo mismo frente a la pérdida de ingresos de la PSD. Apenas en el caso Bellavista (2010) atinó a decir que se habían causado, pero advirtió que no se encontraba en condiciones de hallar su monto. Curiosamente, en este caso, no apeló al recurso de liquidar el perjuicio con base en el salario mínimo, como ya lo venía haciendo tradicionalmente en aquellos eventos en los que no era posible averiguar cuál era el ingreso percibido por la víctima antes del daño.

Frente al perjuicio moral, el juez se orientó a calificarlo como un hecho notorio que ocurría cuando el despojo causaba dolor, angustia y desolación, al ver menguada la condición económica, social y cultural. El daño por alteración a las condiciones de existencia (ACE) (también considerado hecho notorio) se identificó como la consecuencia del cambio involuntario de domicilio, pues asumió que generaba una alteración brusca y trascendental de las condiciones de vida de la persona en cuanto tal.

\subsubsection{En cuanto a la imputación del daño}

En todos los casos estudiados, coincidieron al afirmar la responsabilidad del Estado por falla del servicio. Asumieron que se presentó al confluir tres circunstancias: primero, la existencia de una obligación de protección a la población civil. Segundo, la verificación de una omisión de las autoridades al no aprovechar todos los recursos disponibles para evitar el desplazamiento. Tercero, la constatación de la importancia causal de dicha omisión en el resultado: de haber actuado, seguramente se habría evitado el éxodo. En el caso Bellacruz (2010), las exigencias hechas por el juez fueron las mismas, pero consideró que la falla se configuró al desconocer el Estado sus obligaciones de protección en posición de garante de la población víctima del desplazamiento.

El juez fue ágil al identificar un mandato de protección en normas internacionales, constitucionales y legales. Apeló a la Convención Interamericana de Derechos Humanos para determinar que las autoridades militares y de policía existían para salvar los derechos de la población civil (como la vida y la libre circulación por el territorio nacional) de cualquier ataque jurídicamente injustificado. Tal mandato se reforzó con los artículos $2^{\circ}$ y 217 de la Constitución, y $2^{\circ}$ y $7^{\circ}$ de la Ley 387 de 1997, que imponen al Estado la obligación de prevenir cualquier forma de desplazamiento. 
Sobre la omisión en el cumplimiento del mandato de protección, las sentencias fueron bondadosas al mostrar un completo inventario de medios de prueba que ponían en evidencia la negligencia de las autoridades. Todos los casos fueron crónicas de un éxodo anunciado, porque organizaciones internacionales, gubernamentales y comunitarias advirtieron con angustia la amenaza paramilitar sobre la población. El Ejército y la Policía participaron como convidados de piedra, permitieron retenes ilegales en la vía pública, masacres y quemas de viviendas, a escasa distancia de sus centros de operación militar.

En algunos eventos, como el de Filogringo (2007), las entidades adujeron la imposibilidad de controlar la arremetida paramilitar: frente a un nutrido grupo de hombres armados, poco podían hacer unos cuantos soldados y policías. No obstante, pese al reconocimiento de dicha imposibilidad inmediata, el juez condenó por el hecho de no aprovechar los recursos físicos y humanos disponibles en el resto del país.

Sobre la relación causal entre la omisión y el daño, el juez hizo el ejercicio mental de pensar en las circunstancias del éxodo si las autoridades hubiesen intervenido. Encontró que los recursos tácticos y físicos del Ejército y la Policía eran suficientes para impedir la llegada de grupos paramilitares y evacuar a la población en condiciones de seguridad, pues conocían las amenazas de incursión armada con suficiente tiempo de antelación.

\subsubsection{En cuanto a la reparación del daño}

Buena parte de las órdenes de reparación se profirieron desde el paradigma tradicional de la REPE. La indemnización fue el principal remedio ofrecido en las sentencias que definieron acciones de grupo. Una sola salió del esquema tradicional en este sentido (caso Bellacruz, 2010). A pesar de la multitud de decisiones y normas internacionales, el juez dio cumplimiento estricto a la Ley 472 (1998) en su artículo 46: "La acción de grupo se ejercerá exclusivamente para obtener el reconocimiento y pago de la indemnización de los perjuicios" [subrayado agregado].

En cuanto a los daños que se indemnizaron, pudimos advertir una tendencia hacia la reparación de los inmateriales. Con los patrimoniales, siempre se puso de presente el problema de su prueba. Para remediar los perjuicios morales y por ACE, se utilizaron los mecanismos de tasación 
tradicionales: en escalas de salarios mínimos con topes de 100. Los montos individuales se reconocieron de manera uniforme, sin distinciones de ninguna naturaleza.

Para ordenar las reparaciones de los patrimoniales, el juez exigió su prueba. En algunos casos, se rehusó porque las víctimas no la presentaron (caso La Gabarra, 2006) o interpusieron la apelación sin argumentos suficientes (caso Alto Naya, 2007). En otros, decidió conceder algún monto bajo el criterio de equidad, sin discriminar si era a título de emergentes o lucrocesantes (caso Filogringo, 2007). Solo en el fallo Bellacruz (2010) se superó el obstáculo probatorio y se ordenó adelantar un incidente posterior para fijar el monto del daño.

El juez procuró proteger la naturaleza indemnizatoria de sus remedios. De un lado, advirtió que los montos reconocidos no podrían modificarse por el hecho del retorno de las víctimas (caso La Gabarra, 2006). Del otro, fue enfático al afirmar que no se descontarían de la indemnización aquellos montos de dinero entregados por la Red de Solidaridad Social. La primera era la consecuencia lógica de la REPE, mientras que la segunda obedecía al trato solidario que el Estado brindaba a las víctimas del DEFO (caso Filogringo, 2007).

El juez evidenció una preocupación por integrar el grupo de accionantes. Sin embargo, su esfuerzo se orientó a verificar si quienes se decían desplazados en realidad lo eran. No mostró mucho interés por ubicar de oficio al resto de víctimas que no demandaron (caso La Gabarra, 2006; caso Alto Naya, 2007).

Procedamos entonces a revisar cuáles fueron las inquietudes de los académicos inspiradas en la declaratoria del ECI para mejorar las condiciones de las víctimas en eventos de reclamación judicial de reparación.

\subsection{Principales preocupaciones de los académicos (líneas de fuga teórica) frente a las condiciones de reclamación judicial de reparación de las víctimas del DEFO, inspiradas en la declaratoria del ECI en 2004}

Buena parte de las propuestas teóricas están inspiradas en nichos teóricos de otras disciplinas, como la ciencia política, la psicología o la teoría social. Como lo advirtió la profesora María Teresa Uribe (2001), las mejores soluciones al desplazamiento llegan cuando se concibe el problema desde 
una perspectiva interdisciplinar. En ese orden, haremos un breve relato de las sugerencias de los teóricos cuya preocupación fue mejorar el canal judicial de reparación de las víctimas del DEFO. Lo haremos teniendo en cuenta los conceptos centrales de la REPE: daño, imputación y reparación.

\subsubsection{Líneas de fuga propuestas para ajustar el concepto del daño}

Para Esteban Restrepo (2009) y David Suárez (2010), es necesario ampliar el alcance del concepto del daño, porque resulta una categoría incompleta. Un perjuicio definido en términos de afectación a objetos dentro o fuera del patrimonio de la víctima no deja ver que el desplazamiento -y su ignorancia por parte de las autoridades- es un desprendimiento forzado del tejido social del ciudadano y deja secuelas de orden cultural, político y ético.

Restrepo tuvo en cuenta la teoría tridimensional de la justicia, propuesta por Nancy Fraser (1997; 1997), y aseguró que la PSD ha sufrido una triple injusticia: de distribución, de reconocimiento y de representación (Fraser, 2008, pp. 15-64). La primera se evidenció en la distorsión que operó sobre la distribución de recursos cuando se les despojó de sus bienes (Ibáñez, 2008; 2009). La segunda, en el tratamiento que recibieron las víctimas por parte de la sociedad, las autoridades y los actores armados: en los tres casos se les ha atribuido una identidad que no corresponde con su tragedia, ya sea como oportunistas (2009), damnificados (Vidal, 2007) o colaboradores del enemigo (Lair, 2004), respectivamente. La tercera, en el poco eco que tuvieron las voces del desplazamiento en el concierto institucional: dificultades logísticas para convocar a una población tan fragmentada, el lenguaje excesivamente técnico o las amenazas impunes de los victimarios son algunas de las razones por las que la voz del desplazado tiene poco eco en el concierto institucional (Rodríguez y Rodríguez, 2010, p. 188).

Para Suárez (2010), la definición jurídica del daño moral le hace poco honor a su nombre. Se trata de un término ideado para señalar aquellos perjuicios que recaen sobre intereses distintos a los que tienen representación económica (lo extrapatrimonial). Se ignora que las víctimas del DEFO se enfrentan a la destrucción de aquellos sistemas de valores construidos en colectividades pequeñas, como el barrio, la escuela o el pueblo. Esta reinterpretación del daño moral obligaría a pensar en la necesidad de plan- 
tear esquemas de reparación que faciliten la reconstrucción axiológica de la población, a través de la reconstrucción de sus relaciones de 'membresía' más pequeñas y significativas (vereda, barrio, escuela).

En este orden, identificamos tres líneas de fuga: daño económico, cultural y político. Desde la perspectiva de la justicia como distribución (Fraser, 1997), el desplazamiento significaría una alteración en el reparto de recursos materiales que existía antes del despojo. La falta de atención por parte de las autoridades representa la prolongación de esta distribución distorsionada. A esta circunstancia la denominaremos daño económico.

Desde la justicia como reconocimiento (Fraser, 1997), podríamos evidenciar un daño cultural en tres variables: desconocimiento y estigma institucional, desconocimiento y estigma social e imposición de una identidad relacionada con el enemigo. Las dos primeras tendrían que ver con la forma despectiva y excluyente en que las autoridades y los demás ciudadanos tratan a las víctimas del desplazamiento como damnificados de desastres naturales u oportunistas. La tercera, con la reputación creada por los victimarios, que ven en el desplazado a un colaborador del bando enemigo.

Finalmente, desde la justicia como representación (Fraser, 2008), tendríamos un daño político representado en dos variables: pérdida de la capacidad de interlocución con las autoridades y pérdida de la capacidad de organización y asociación para superar la tragedia humanitaria. La primera de ellas implicaría un deterioro grave de los canales de participación ciudadana: quien se ve obligado a migrar pierde las oportunidades y los escenarios para utilizar algunos mecanismos como el voto, o ser protagonista de procesos como la consulta popular, por ejemplo. La segunda estaría relacionada con la destrucción de las relaciones comunitarias que permitían la subsistencia de las víctimas: escuela, juntas de acción comunal, asociaciones de vecinos o acueductos veredales, por ejemplo.

\subsubsection{Líneas de fuga propuestas para ajustar el concepto de imputación}

Las inquietudes de los profesores nos permitieron dilucidar dos líneas de fuga en este punto. Apuntaron a la necesidad de buscar soluciones a dos problemas: las limitaciones conceptuales de los regímenes de responsabilidad estatal y la insuficiencia de recursos para reparar a las víctimas como una razón para exonerar al Estado de cualquier responsabilidad. 
En cuanto al primer problema, los profesores Sepúlveda (2002) y Peláez (2007) dieron voces de alerta en materia de imputación: los regímenes de responsabilidad ostentan limitaciones importantes. Los de tipo objetivo, como el daño especial y el riesgo excepcional, no resultan aplicables sino en aquellos eventos de intervención directa y legítima de las autoridades. Es decir que en casos de omisión tendría que recurrirse a títulos subjetivos como el de falla del servicio.

Pero estos últimos implican cargas probatorias excesivas para las víctimas, pues ante el éxodo el Estado solo sería declarado responsable al omitir las medidas de cuidado y protección de la población civil, dentro de los límites de lo física y jurídicamente posible. Es decir, solo aquel éxodo que resulte ser un hecho previsible y resistible podría dar lugar a una declaración de responsabilidad. La dificultad radica en que las pruebas de dichas circunstancias les corresponden, en principio, a las víctimas (Peláez, 2007).

En cuanto al segundo problema, el profesor Dueñas (2009) evidenció que, a pesar del ECI, las autoridades no asumieron cambios contundentes en la política pública (Dueñas, 2009, p. 24). La profesora Cortés (2005) encontró que, entre la política de seguridad democrática y la de prevención y atención al DEFO, existió una relación estrecha determinada por el aspecto presupuestal: la robusta financiación de la primera fue un pretexto para el estancamiento de la segunda, en detrimento de los derechos fundamentales de la población desplazada (Cortés, 2005, p. 144).

Aparecen en el panorama dos líneas de fuga teóricas. La primera de ellas consiste en recurrir a una herramienta para aligerar el peso de la carga procesal de la víctima: la presunción de falla del servicio en aquellos eventos de éxodo. La segunda, en considerar la omisión en la búsqueda de recursos (humanos, económicos e institucionales) para la política pública de atención a la PSD, como un caso de inactividad administrativa que dé lugar a la falla del servicio, que también debería presumirse.

Presumir la falla del servicio implica invertir las cargas de la prueba para aliviar a quienes tienen menores posibilidades de probar. ${ }^{3}$ De atender la sugerencia, ya no serían las víctimas las encargadas de verificar la partici- 
pación del Estado en el éxodo, sino que se tendría por cierta hasta que las autoridades demostraran lo contrario. Aunque la medida se muestra en principio desventajosa, se trata de un desequilibrio en favor de los menos aventajados en el debate procesal, exigido por las normas del derecho internacional (ONU, 2006, pp. Ib-IIc).

Considerar la omisión en la búsqueda de recursos para la política pública de atención a la PSD, como un caso de inactividad administrativa que dé lugar a la falla del servicio (Gómez, 2000), sería una forma de presionar al Estado para que, dentro de sus planes de política económica, el desplazado no se torne en aplazado. Exonerar por el hecho de no contar con los recursos suficientes desestimula la búsqueda de los medios que permitan superar el ECI.

Resulta más fácil para las autoridades probar la diligencia en el cumplimiento del deber de progresar que para las víctimas verificar una omisión en este sentido. La condición de vulnerabilidad que vive la víctima la pone en una situación de difícil acceso a toda la información necesaria para configurar los elementos de la inactividad administrativa. Es por esto por lo que proponemos que también se deje en manos del Estado la carga probatoria (López, 2013).

\subsubsection{Lineas de fuga propuestas para ajustar la reparación ${ }^{4}$}

Varios académicos y organizaciones han manifestado sus inquietudes en torno a la reparación de las víctimas del DEFO. Aunque el concepto ha sido ampliado por los estándares internacionales, consideran que debe ser ajustado a la realidad colombiana. Uno de ellos es el profesor Rodrigo Uprimny y el grupo de investigadores de Dejusticia (Uprimny y Saffón, 2009; 2010; Uprimny y Sánchez, 2010), para quienes es necesario hablar de reparaciones transformadoras. Con esta expresión, se refieren a un ejercicio de reparación en el que los remedios se aplican sobre el daño con un doble propósito: restaurar a las víctimas y transformar su circunstancia de vulnerabilidad y discriminación.

4 En esta oportunidad, tuvimos que presentar una síntesis muy apretada de las líneas de fuga por razones de espacio. El desarrollo completo del tema se encuentra en el documento de tesis de maestría, disponible en http://repository.urosario.edu.co/handle/10336/4783 
Es una apuesta por el ajuste de cuentas (justicia correctiva), pero también por la construcción de una sociedad más democrática (justicia distributiva). El enfoque correctivo se evidencia en dos circunstancias. Una de ellas es que la fuente de la reparación siempre será el perjuicio ocasionado, no puede haber reparación sin daño. La otra es que solo podrán beneficiarse las víctimas, los demás ciudadanos no pueden acceder a la reparación. El enfoque distributivo se muestra en el hecho de que los remedios deben tener la virtud de corregir aquellas situaciones de vulnerabilidad y discriminación que facilitaron la ocurrencia del daño (Uprimny y Saffón, 2009; 2010; Uprimny y Sánchez, 2010).

Otros académicos evidenciaron la necesidad de adecuar los remedios ofrecidos a las víctimas. A su juicio, la reparación debe tener un alcance colectivo, simbólico, participativo, diferencial, regional y de corrección temporal.

En primer lugar, como lo evidenció la profesora Rincón (2010), la reparación debe tener alcance colectivo. Ello implica reconocer, por una parte, que las víctimas conviven en agrupaciones, ya sea que compartan o no características culturales e históricas previas. ${ }^{5}$ También, que es necesario pensar en remedios colectivos directos, como la titulación de tierras a comunidades o la producción de cambios institucionales, pero también indirectos, como aquellas medidas simbólicas individuales que involucran la memoria de la colectividad. En el ámbito judicial, la reparación con alcances colectivos implicaría que el juez profiriera órdenes de reparación que beneficiaran a la comunidad y ampliara la extensión de los remedios individuales a los demás afectados, aun a aquellos que no demandaron (Londoño y Carrillo, 2010).

En segundo lugar, un remedio con alcances simbólicos se traduciría en un acto de reconciliación entre el Estado y sus ciudadanos excluidos. No puede quedarse en la simple entrega de sumas de dinero. Es por eso que los remedios deben ofrecerse con la intención de recuperar los derechos vulnerados, rescatar la verdad oculta detrás del despojo y concretar la justicia esquiva hacia los victimarios. En el escenario judicial, implicaría 
decretar medidas concretas de no repetición, rehabilitación y satisfacción para sanar los daños morales, a la salud y a la vida de relación, y enfocar la indemnización hacia el cubrimiento exclusivo de daños materiales (emergente y lucro cesante) (López, 2010).

En tercer lugar, la reparación debe tener alcances participativos, esto es, producirse en contextos en los que las víctimas puedan contribuir en el diseño e implementación de los remedios. Dos razones lo justifican, una es de orden práctico: como los recursos son escasos, su aprovechamiento implica sacrificios que deben discutirse. La otra es de naturaleza ética y jurídica: las víctimas deben ser tratadas con humanidad (Uprimny, Sánchez y Bolívar, 2010).

Una sentencia de responsabilidad estatal podría asegurar la reparación en términos participativos abriendo espacios de diálogo con las víctimas y las autoridades antes de dar un fallo definitivo. En este orden de ideas, podría dar a conocer el sentido de su decisión antes de proferirla. Si esta resultare favorable a los demandantes, debería proseguir con la celebración de una audiencia pública de discusión en la que víctimas y entidades demandadas pudieran exponer sus preferencias sobre los límites y formas de reparación. En el artículo 61 de la Ley 472 de 1998, se contempló una posibilidad similar, pero para intentar la conciliación antes del período probatorio.

En cuarto lugar, los profesores Rodrigo Uprimny, Camilo Sánchez (2010) y César Rodríguez (Rodríguez, Alfonso y Cavelier, 2009) consideraron que los remedios deben responder a las afectaciones concretas y singulares de cada una de las víctimas, teniendo en cuenta sus necesidades y condiciones de vulnerabilidad particulares. La razón más fuerte para buscar una reparación con alcances diferenciales es que la enfermedad tiene impactos distintos en todas sus víctimas, luego es imposible curarla definitivamente con una misma medicina. Sin este criterio, cualquier esfuerzo se convierte en una cura ciega, más peligrosa que la misma enfermedad.

Traducido al ámbito judicial, la reparación con enfoque diferencial implicaría que el juez, al definir los efectos del fallo, rescatara las diferencias entre víctimas para brindar remedios distintos. La sentencia debería tener en cuenta las condiciones de vulnerabilidad previas al despojo y no solamente la magnitud del daño. Algunos indicadores que podría evaluar serían: género y edad de la víctima, pertenencia a grupos étnicos, ingreso promedio, 
relación de propiedad inmueble, vinculación laboral, nivel de escolaridad, situación de vivienda, vinculación al sistema de salud, entre otros.

En quinto lugar, los académicos han manifestado una preocupación al evidenciar que la política pública de protección a las víctimas del DEFO se ha construido con escasa participación de los departamentos y municipios (Riveros, 2009; Pedraza y Restrepo, 2009; Jolly, 2007). Por eso, la reparación debe tener alcances y enfoques regionales. En el contexto judicial, ello implicaría que se integraran al litigio a todas aquellas autoridades que cuenten con alguna competencia en la prevención del DEFO y atención de la PSD, aunque no hayan sido relacionadas directamente con la demanda. ${ }^{6}$

Finalmente, para nadie es un misterio que la justicia contenciosa es una de las más lentas. Tan solo en Bogotá y Cundinamarca los estudios han arrojado resultados espeluznantes: un promedio de 9 años (108 meses) es el término empleado para resolver un asunto de responsabilidad extracontractual en dos instancias; el promedio de duración de la primera instancia fue de 2,9 años (35 meses), mientras que el de la segunda osciló sobre los 5,7 años (69 meses) (López, Alviar y Rodríguez, 2007, p. 81). La cifra de procesos de responsabilidad estatal pendientes de sentencia en los anaqueles de los juzgados administrativos de Bogotá era de 8.120 para el año 2008 y de 3.735 en el Tribunal Administrativo de Cundinamarca (Restrepo, Younes, Ruiz y Tavera, 2009). Para superar los cuellos de botella, el equipo dirigido por el profesor Restrepo (2009) propuso tomar medidas en torno a tres frentes: la reducción de la demanda de acceso a la justicia, reformas procesales para agilizar los procedimientos y cambios administrativos para mejorar la gestión de los despachos.

Para brindar respuestas que agilicen los procedimientos, consideramos que el juez debería dar trámite preferente a las demandas de reparación de la PSD, sea en el curso de una acción de grupo o de la reparación directa. Es decir que la decisión en estos casos llegue antes que para otras pretensiones

6 Los departamentos y municipios siempre han tenido un papel protagónico en las normas diseñadas para prevenir el DEFO y atender a la PSD. En la Ley 387 (Congreso de la República, 1997), por ejemplo, recibieron el encargo de crear y gestionar comités municipales, distritales y departamentales para la atención integral a la población desplazada por la violencia (art. $7^{\circ}$ ). En la Ley 1190 (Congreso de la República, 2008), el de diseñar e implementar planes integrales únicos (PIU) para gestionar mejor los recursos institucionales y financieros (art. $2^{\circ}$ ). En la 1448 (Congreso de la República, 2011), se hicieron cargo de tareas centrales, como la prestación de servicios de asistencia humanitaria y otros complementarios a los mecanismos de reparación (arts. 172 a 174). 
de responsabilidad, aunque estas últimas se hayan interpuesto primero. No podemos ignorar que medidas como estas podrían causar traumatismos en el trámite del resto de acciones, pero tampoco debemos pasar por alto que se trata de un sector de la población sobre el que recaen injusticias más complejas. Darle prioridad a sus reclamos haría parte de las medidas de inclusión necesarias para evitar que se prolongue su invisibilidad. La sentencia oportuna serviría para promover la confianza de las víctimas en el Estado.

La última línea de fuga que delineamos no fluye directamente de las propuestas académicas inspiradas en la declaratoria del ECI en 2004. Se trata de una reflexión propia. Sin embargo, cuenta con suficiente respaldo en normas internacionales: la Convención Americana de Derechos Humanos (OEA, 1969) señala, en su artículo 25, que el derecho del ciudadano a la protección judicial conlleva la existencia de recursos sencillos y rápidos ante los jueces. Por ello, debería ser objeto de protección inmediata a través de la acción de tutela. En otras palabras, si el juez contencioso no diera trámite preferente a las pretensiones de reparación de la PSD sobre las del resto de ciudadanos en condiciones distintas al DEFO, las víctimas deberían contar con el recurso de amparo para conminarlo a decidir primero su demanda.

Una vez identificadas las líneas de fuga teórica, nos corresponde ahora revisar qué tan sensible fue el Consejo de Estado a estas propuestas académicas, cuando proyectó sus sentencias de responsabilidad estatal por desplazamiento.

\subsection{Impacto de las propuestas académicas (líneas de fuga teórica) sobre los argumentos del Consejo de Estado al definir la responsabilidad de las autoridades por desplazamiento forzado entre 2004 y 2010}

En aras de revisar en qué magnitud el juez tuvo en cuenta las líneas de fuga, procedimos a medir su impacto a través de la escala de fuga teórica y el índice de fuga teórica.

La primera nos permitió establecer el nivel de asimilación que tuvieron las líneas de fuga sobre cada argumento del juez. Solamente evaluamos los que consideramos de vital importancia en la estructura de la decisión y que además evidenciaron algún asomo de ampliación de los cánones tradiciona- 
les de la REPE; es decir, aquellos sin los cuales el juez no habría llegado a la decisión que tomó y los que presentó más allá de las formulaciones clásicas.

Nos permitimos medir numéricamente cada una de las razones de la sentencia: se evaluaron en términos de impacto alto (1 punto), cuando evidenciábamos que la razón expuesta era sensible a alguna línea de fuga y se reflejaba en las órdenes concretas del fallo; impacto medio ( 0,5 puntos), si se trataba de órdenes sensibles a las líneas pero sin consideraciones que las soportaran; ${ }^{7}$ impacto bajo (0 puntos), cuando estas últimas reflejaban la influencia de las propuestas teóricas pero no ocurría así en las órdenes concretas. En la tabla 1 del anexo, se muestra, a manera de ejemplo, la ficha que usamos para evaluar el fallo Filogringo en la escala de fuga teórica.

El índice de fuga teórica fue propuesto como una evaluación del fallo en su conjunto. Después de evaluar cada argumento del fallo a la luz de la escala de fuga teórica y de darle un valor numérico a dichas valoraciones, sumamos los dígitos para obtener un puntaje total por sentencia. Este último lo usamos para definir el índice de fuga teórica. La medición que propusimos se basó en la comparación entre cada sentencia con una 'decisión ideal' en la que el juez hubiese tenido en cuenta, hipotéticamente, todas las líneas de fuga. Si aplicáramos la escala de fuga teórica a una sentencia en la que el juez siguiera todas las líneas de fuga, en sus consideraciones y órdenes, tendríamos un puntaje total de 18 puntos (ver tabla 2 del anexo). En términos numéricos, se dividió el dígito que obtuvimos después de aplicar la escala a cada sentencia entre 18. La razón es que este es el máximo puntaje que podría obtener un fallo en la medición.

Nuestro índice tiene dos extremos: el de ausencia de fuga teórica y el de máxima fuga teórica. En el primer caso, el valor es 0 , lo que indica que el juez no fue sensible a ninguna de las líneas, porque no se reflejaron en sus órdenes ni en los argumentos que las soportaron. En el segundo, el dígito es 1 , es decir que el autor de la sentencia tuvo en cuenta todas las líneas de fuga para confeccionar sus consideraciones medulares y dar solución al problema jurídico concreto. 
Al aplicar la escala de fuga y el índice, obtuvimos los siguientes resultados:

Tabla 1. Escala de fuga e índice de fuga teórica de los casos estudiados

\begin{tabular}{|l|c|c|}
\hline \multicolumn{1}{|c|}{ Ejemplar } & $\begin{array}{c}\text { A. Resultado de medición en } \\
\text { escala de fuga teórica }\end{array}$ & B. Índice de fuga teórica (A/18) \\
\hline La Gabarra & 1,5 puntos & 0,08 \\
\hline Alto Naya & 1,5 puntos & 0,08 \\
\hline Filogringo & 3,5 puntos & 0,19 \\
\hline Bellacruz & 3 puntos & 0,16 \\
\hline Promedio general & 2,37 puntos & 0,13 \\
\hline
\end{tabular}

En materia de daño antijurídico, el juez contencioso reconoció que el desplazamiento dejó graves secuelas culturales, representadas en el prejuicio social hacia las víctimas, quienes recibieron rótulos trágicos como 'guerrilleros', 'ladrones' o 'mendigos'. Sin embargo, estas consideraciones hicieron parte de la valoración del daño moral, que se pretendió reparar con dinero, sin tener en cuenta que el impacto de dicho estigma social es distinto en cada perjudicado. En últimas, el concepto de daño no dio para pensar en su impacto cultural. El desconocimiento social e institucional de la tragedia, la imposición de identidades relacionadas con el enemigo, se quedaron como párrafos a mitad de camino hacia decisiones que reforzaron el paradigma tradicional.

En ninguna sentencia se tuvo en cuenta el desarraigo político que sufrieron las víctimas. Buena parte de los antecedentes de cada fallo dejaron ver que las comunidades afectadas contaban con algunos canales de interlocución institucional y cierta capacidad de organización y asociación. Fue por eso que en casi todos los eventos (caso La Gabarra, 2006; caso Alto Naya, 2007; caso Filogringo, 2007) el desplazamiento se pudo prever y por lo que en otros la PSD pudo retornar con el auspicio del Gobierno nacional (caso Bellacruz, 2010). No obstante, la tragedia humanitaria bloqueó dichas ventajas. ${ }^{8}$ El Consejo de Estado pasó por alto esta circunstancia sin detenerse mucho en sus consideraciones sobre el daño.

8 En la mayoría de los casos estudiados, la interlocución de la comunidad con las Fuerzas Militares fue inexistente. A pesar de las alertas tempranas, aparecieron después de la expulsión para 
En cuanto a la imputación del daño, al definir si el desplazamiento era previsible, por una parte, tuvieron en cuenta que las víctimas hubiesen dado noticia de la probable ocurrencia del hecho. Pero también admitieron la previsibilidad cuando las circunstancias de alteración grave del orden público permitieron inferir que la expulsión de población civil era inminente. En este sentido, las víctimas se descargaron de la obligación probatoria. ${ }^{9}$ Por otra parte, la redacción de las sentencias dejó ver que era una obligación del Estado probar la imposibilidad de cumplir su deber de protección. Los jueces fueron enfáticos en exigir dicha prueba con rigor. ${ }^{10}$

Los argumentos fueron escasos en cuanto a la responsabilidad estatal por la omisión en la búsqueda de recursos para la política pública. Curiosamente, el juez reconoció la negligencia de las autoridades 'el día después del éxodo', pero tal gesto no se vio representado en las condenas. El argumento central de la falla siguió siendo la inactividad administrativa en el momento del desplazamiento.

Finalmente, en cuanto a las propuestas sobre reparación, debemos advertir que el juez tuvo en cuenta solamente dos dimensiones: la colectiva y la simbólica. En primer lugar, en cuanto a la reparación con alcances colectivos, los jueces de las acciones de grupo hicieron énfasis en el hecho de que sus fallos definían la situación de todos los perjudicados, aun la de quienes no hubiesen intervenido en el proceso. Fue por ello que dejaron de aplicar algunos apartes del artículo 55 de la Ley 472 de 1998, para permitir que las víctimas se beneficiaran de la indemnización. En concreto, el que impedía acceder a los beneficios del fallo a aquellos que no habían demandado pero cuyos recursos individuales ya estaban caducados.

registrar el hecho. En el caso La Gabarra, por ejemplo, la población tuvo que reaccionar huyendo ante la inactividad de las Fuerzas Militares. En Alto Naya, la comunidad logró alertar a la Comisión Interamericana de Derechos Humanos y a la Defensoría del Pueblo, pero no tuvo el mismo éxito con el Ejército Nacional. En algunos eventos, como el de Bellacruz, las víctimas tuvieron que salir del país para evitar la muerte al momento de retornar.

9 No se puede pasar por alto que la posibilidad de probar la participación de agentes estatales en el desplazamiento era casi imposible. En todos los casos estudiados, las pruebas de la negligencia de los funcionarios y de su complicidad con los paramilitares se pudieron obtener con las investigaciones de la Fiscalía un año después de los hechos. Con tantos días de distancia, una víctima ya no está en condiciones de llevarle certezas al juez sobre la responsabilidad de los agentes estatales.

10 En los casos de La Gabarra, Filogringo y Bellacruz, las autoridades se limitaron a afirmar la imposibilidad de prever y controlar la expulsión de población. Sin embargo, para el respectivo juez fue un argumento insuficiente que dio pie para hacer un llamado de atención sobre la negligencia estatal. 
En segundo lugar, la reparación con alcance simbólico fue una rareza argumentativa. En todas las sentencias que definieron acciones de grupo, encontramos la orden de publicar el fallo en un medio de amplia circulación nacional. Pero tampoco pudimos ilusionarnos porque los jueces fueron claros al afirmar que estaban cumpliendo el artículo 65 de la Ley 472. La publicación no era vista como una forma de reparación simbólica, sino como un mecanismo para que las víctimas que no habían demandado se integraran al grupo y participaran de la indemnización:

Ley 472 de 1998, artículo 65. Contenido de la sentencia. La sentencia que ponga fin al proceso se sujetará a las disposiciones generales del Código de Procedimiento Civil y además, cuando acoja las pretensiones incoadas, dispondrá: 4. La publicación, por una sola vez, de un extracto de la sentencia, en un diario de amplia circulación nacional, dentro del mes siguiente a su ejecutoria o a la notificación del auto que hubiere ordenado obedecer lo dispuesto por el superior, con la prevención a todos los interesados igualmente lesionados por los mismos hechos y que no concurrieron al proceso, para que se presenten al juzgado, dentro de los veinte (20) días siguientes a la publicación, para reclamar la indemnización [subrayado agregado].

Solamente en la sentencia que definió la acción de reparación directa (caso Bellacruz, 2010) pudimos apreciar medidas de reparación simbólica. Con el argumento de que el DEFO atentaba contra derechos humanos, el juez se lanzó a la aventura de protegerlos a través de medidas de justicia restaurativa. Por eso, profirió órdenes de satisfacción y de no repetición como la publicación del fallo en las entidades demandadas, la instalación de una placa conmemorativa y la capacitación de funcionarios públicos. Además, llamó la atención de la Fiscalía para que tomara las medidas pertinentes en aras de evitar la impunidad y asegurar la verdad.

\section{Conclusiones}

Después de apreciar el edificio numérico que construimos, la conclusión salta a la vista. En los casos que estudiamos, buena parte de sus órdenes y argumentos más luminosos, que parecieran renovar el paradigma de la 
REPE, reflejaron un impacto bajo de las líneas de fuga. Casi todos los planteamientos se quedaron en consideraciones auxiliares que no trascendieron a las órdenes concretas del fallo.

Si miramos el índice de fuga, de cada ejemplar y en conjunto, dimensionamos mejor la distancia tan grande que existió entre los fallos del Consejo de Estado y las líneas de fuga teórica. En otros términos, los números nos permitieron afirmar que la práctica judicial de la REPE no satisfizo las exigencias teóricas que surgieron del estudio del DEFO en Colombia: el juez fue amplio considerando, pero tímido fallando. Nos queda un reto pendiente al finalizar esta tarea y se resume en un interrogante corto pero inquietante: ¿por qué?

\section{Referencias}

\section{Bibliográficas}

Acnur. (2007, mayo 7). Recomendación de criterios de reparación y de proporcionalidad restaurativa. Recuperado de http://www.acnur.org/t3/recursos/informacionsobre-pais-de-origen/detalle-documento-coi/recomendacion-de-criterios-dereparacion-y-de-proporcionalidad-restaurativa/

Araújo, R. (2011). Acceso a la justicia efectiva. Propuesta para fortalecer la justicia administrativa. Visión de derecho comparado. Estudios Socio-jurídicos, 13(1), 247-291.

Cancado, A. (2006). Responsabilidad, perdón y justicia como manifestaciones de la consciencia jurídica universal. Estudios Socio-jurídicos, 8(1), 15-36.

Cifuentes, E. (1996). Salvamento de voto a la Sentencia C-263 de 1996. Bogotá: Corte Constitucional.

Codhes. (marzo, 2012). Desplazamiento creciente y crisis humanitaria invisibilizada. Codhes Informa. Boletín de la Consultoria para los Derechos Humanos y el Desplazamiento Forzado, (79). Recuperado de http://www.acnur.org/t3/uploads/media/ CODHES_Informa_79_Desplazamiento_creciente_y_crisis_humanitaria_invisibilizada_Marzo_2012.pdf?view=1

Codhes. (diciembre, 2012). Desplazamiento creciente y crisis humanitaria invisibilizada. Codhes Informa. Boletín de la Consultoría para los Derechos Humanos y el Desplazamiento Forzado, (80). Recuperado dehttp://www.codhes.org/index. php?option $=$ com_docman\&task $=$ cat_viewEgid $=64 \xi I t e m i d=50$ 
Comisión de Seguimiento a la Política Pública sobre Desplazamiento Forzado. (2009). Décimo primer informe: cuantificación y valoración de las tierras y los bienes abandonados o despojados a la población desplazada en Colombia. Bases para el desarrollo de procesos de reparación. Recuperado de http://www.nrc.org.co/ docs/Xlinformecomisiondeseguimientoppdenero2009.pdf

Comisión de Seguimiento a la Política Pública sobre Desplazamiento Forzado. (2010). Tercer informe de verificación sobre el cumplimiento de derechos de la población en situación de desplazamiento. Recuperado de http://www.codhes.org/ index.php?option $=$ com_contentEtask $=$ viewEid $=39$ Eltemid $=52$

Comisión de Seguimiento a la Política Pública sobre Desplazamiento Forzado. (2011). El reto ante la tragedia humanitaria del desplazamiento forzado: reconocery resarcir debidamente los daño y perjuicios. Volumen 10. Bogotá: Consultoría para los Derechos Humanos y el Desplazamiento Forzado (Codhes).

Cortés, J. (2005). Análisis de la atención a la población desplazada por la violencia desde el punto de vista presupuestal (Tesis de grado para optar por el título de Abogado, Colegio Mayor de Nuestra Señora del Rosario, Bogotá, Colombia).

Dangond, J. (1981). Responsabilidad extracontractual del Estado. En J. López, Responsabilidad extracontractual del Estado, ochenta años de jurisprudencia (pp. 481-524). Bogotá: Ediciones Lex.

De Cupis, A. (1970). El daño. Barcelona: Bosch.

De Greiff, P. (2006). Justice and reparations. En P. de Greiff, The handbook of reparations (pp. 451-477). New York: Oxford University Press.

Departamento Nacional de Planeación. (2011). Documento Conpes 3712: plan de financiación para la sostenibilidad de la Ley 1448. Recuperado de http://www. dnp.gov.co/LinkClick.aspx?fileticket=tbxvV6M0DGg\%3DEtabid=1080

Deutsche Gesellchaft für Technische Zusammenarbert (GTZ). (2010). Daño y reparación judicial en el ámbito de la Ley de Justicia y Paz. Bogotá: Embajada de la República Federal Alemana.

Dueñas, Ó. (2007). Lecciones de hermenéutica jurídica. Bogotá: Editorial Universidad del Rosario.

Dueñas, Ó. (2009). Desplazamiento interno forzado: un estado de cosas inconstitucional que se agudiza. Efectos de la Sentencia T-025 de 2004 de la Corte Constitucional. Bogotá: Editorial Universidad del Rosario.

Elster, J. (2010). Land, justice and peace. En M. Bregsmo, C. Rodríguez, E M. P. Saffón, Distributive justice in transitions (pp. 12-23). Oslo: Torkel Opsahl Academic E Publisher and Peace Research Institute Oslo.

Fraser, N. (1997). Iustitia interrupta. Reflexiones críticas desde la posición 'postsocialista'. Bogotá: Siglo del Hombre. 
Fraser, N. (1997). La justicia social en la época de la política de la identidad: redistribución, reconocimiento, participación. En N. Fraser, Estudios Ocasionales Cijus. Cátedra Ciro Angarita Barón (pp. 9-29). Bogotá: Universidad de los Andes.

Fraser, N. (2008). Escalas de justicia (traducción de Antoni Martínez Rui). Barcelona: Herder.

Garay, L. J., E Vargas, F. (2012). Memoria y reparación: elementos para una justicia transicional pro víctima. Bogotá: Universidad Externado de Colombia.

García, M., E Saffón, M. P. (2011). Derechos sociales y activismo judicial. La dimensión fáctica del activismo judicial en derechos sociales en Colombia. Estudios Sociojurídicos, (1), 75-107.

Ghersi, C. (1995). Modernos conceptos de responsabilidad civil. Bogotá: Biblioteca Jurídica Diké.

Ghersi, C. (2013). Teoría general de la reparación de daños. Análisis epistemológico del daño económico y extraeconómico. Relación de causalidad y factores de atribución. Violación de confianza. Tercerización. Abuso de marca. Incumplimiento de tratados internacionales. Bogotá: Astrea-Universidad del Rosario.

Gómez, M. (2000). La inactividad de la administración. Madrid: Aranzadi.

Guataquí, J. C. (2009). La dimensión del desplazamiento en Colombia: la problemática del sistema de registro y caracterización de la población desplazada. En C. Rodríguez, Más allá del desplazamiento. Políticas, derechos y superación del desplazamiento forzado en Colombia (pp. 39-71). Bogotá: Universidad de los Andes.

Henao, J. C. (1998). El daño. Análisis comparativo de la responsabilidad extracontractual del Estado en derecho colombiano y francés. Bogotá: Universidad Externado de Colombia.

Huici, L. (2007). El hecho internacionalmente ilícito de las organizaciones internacionales. El proyecto de la Comisión de Derecho Internacional sobre la responsabilidad de las organizaciones internacionales. Barcelona: Bosch.

Ibáñez, A. M. (2008). El impacto del desplazamiento forzoso en Colombia: condiciones socioeconómicas de la población desplazada, vinculación a los mercados laborales y políticas públicas. Serie Políticas Sociales. Bogotá: Comisión Económica para América Latina (Cepal).

Ibáñez, A. M. (2009). El desplazamiento forzoso en Colombia. Un camino sin retorno hacia la pobreza. Bogotá: Universidad de los Andes.

Jolly, J. (2007). Territorialidad y sectorialidad de las políticas públicas. Aspectos analíticos y utilizaciones normativas de un esquema de análisis de las políticas públicas en el territorio. En J. Jolly, E J. I. Cuervo, Ensayos sobre politicas públicas (pp. 289-349). Bogotá: Universidad Externado de Colombia. 
Lair, E. (2004). El terror, recurso estratégico de los actores armados. En E. Pizarro, Guerra en Colombia: actores armados (pp. 131-161). Bogotá: Instituto de Estudios Políticos y Relaciones Internacionales (Iepri).

Londoño, B., E Carrillo, A. (2010). Acciones de grupo y de clase en casos de graves vulneraciones a derechos humanos. Recuperado de http://www.defensoria.org. co/red/anexos/publicaciones/accionesGrupo.pdf

López, D. E., Alviar, H., E Rodríguez, C. (2007). Estudio diagnóstico de la actividad litigiosa de la nación en su componente transversal 'gestión jurídica de la nación' (informe final de investigación presentado al Ministerio del Interiory de Justicia) iJusticia mediante litigio? Bogotá: Centro de Estudios de Derecho, Justicia y Sociedad (Dejusticia).

López, C. (2010). La acción de grupo: mecanismo adecuado y efectivo para reparar graves violaciones a los derechos humanos (Tesis de Maestría en Derecho Administrativo, Universidad del Rosario, Bogotá, Colombia).

López, M. A. (2013). Exploración conceptual de la responsabilidad del Estado frente al desplazamiento forzado. Aplicación de la teoría de las revoluciones científicas a eventos de responsabilidad patrimonial del Estado por desplazamiento forzado. Recuperado de http://repository.urosario.edu.co/bitstream/handle/10336/4783/1057577970-2013.pdf?sequence=1 GisAllowed=y

Mir, O. (2002). La responsabilidad patrimonial de la administración. Hacia un nuevo sistema. Madrid: Civitas.

Montes, C. (1998). La estructura y los sujetos de la obligación. Madrid: Civitas.

Navia, A. F. (2001). Del daño moral al daño fisiológico. ¿Una evolución real? Bogotá: Universidad Externado de Colombia.

Pedraza, B., E Restrepo, D. (2009). Las entidades territoriales en la realización de los derechos de la población desplazada. Limitaciones y posibilidades de los entes territoriales frente al estado de cosas inconstitucional. Bogotá: Consultoría para los Derechos Humanos y el Desplazamiento (Codhes).

Peláez, J. C. (2007). Los límites del derecho de la responsabilidad extracontractual del Estado en materia de desplazamiento forzado. En A. J. Arnaud, Cátedra Unesco. Derechos humanos y violencia: gobierno y gobernanza. El desplazamiento forzado interno en Colombia: un desafio a los derechos humanos (pp. 277-302). Bogotá: Universidad Externado de Colombia.

Peña, C. (2011). Reparación integral. Consideraciones críticas. Una aproximación a la jurisprudencia del Consejo de Estado de la Corte Interamericana de Derechos Humanos. Bogotá: Veramar.

Petit, E. (2002). Tratado elemental de derecho romano. Bogotá: Esquilo. 
Programa de las Naciones Unidas para el Desarrollo. (2011). Colombia rural. Razones para la esperanza. Informe Nacional de Desarrollo Humano. Bogotá: INDH-PNUD. Programa de las Naciones Unidas para el Desarrollo. (2011). Desplazamiento forzado, tierras y territorios. Agendas pendientes: la estabilización socioeconómica y la reparación. Bogotá: PNUD.

Programa Somos Defensores. (2012). Efecto placebo. Informe anual 2012. Sistema de información sobre agresiones contra defensores y defensoras de derechos humanos en Colombia. Recuperado de http://www.oidhaco.org/uploaded/content/ article/1661103593.pdf.

Programa Somos Defensores. (2013). D de Defensa. Informe anual 2013. Sistema de información sobre agresiones contra defensores y defensoras de derechos humanos en Colombia. Recuperado de http://www.somosdefensores.org/index.php/ extensions/ultimas-noticias/421-informe-siaddhh-2013-d-de-defensa

Quinche, M. (2009). Los estándares de la Corte Interamericana y la Ley de Justicia y Paz. Bogotá: Editorial Universidad del Rosario.

Ramírez, A. C. (2010). Desplazamiento interno forzado en Colombia. Producción académica y política pública. Recuperado de http://www.udenar.edu.co/viceacademica/CICLOS\%20PROPED\%C9UTICOS/CONVENIO\%20ALCALDIA_UDENAR/ TALLER\%20ASPECTOS\%20CURRICULAR/DT\%20PROYECTO/desplazamiento\%20 forzado.pdf

Rebollo, L. M. (2007). Fundamento y función de la responsabilidad del Estado: situación actual y perspectivas. En J. Moreno, La responsabilidad civil y su problemática actual (pp. 539-569). Madrid: Dykinson.

Restrepo, E. (2009). ¿Cómo garantizar justicia a los desplazados? El desplazado como paria. La garantía de los derechos a la verdad, la justicia y la reparación de las víctimas del delito de desplazamiento forzado en Colombia. En C. Rodríguez, Más allá del desplazamiento. Políticas, derechos y superación del desplazamiento forzado en Colombia (pp. 293-430). Bogotá: Universidad de los Andes.

Restrepo, M., Younes, D., Ruiz, F., \& Tavera, M. (2009). Dimensión de la congestión en la jurisdicción administrativa. Análisis y propuestas de solución. Bogotá: Universidad del Rosario.

Reyes, A. (2009). Guerreros y campesinos. Bogotá: Norma.

Rincón, T. (2010). Verdad, justicia y reparación. La justicia de la justicia transicional. Bogotá: Editorial Universidad del Rosario.

Riveros, H. (2009). La eficacia de los derechos de la población en situación de desplazamiento: un desafío para la aplicación de los principios constitucionales de organización territorial. En C. Rodríguez, Más allá del desplazamiento: politi- 
cas, derechos y superación del desplazamiento forzado en Colombia (pp. 261-291). Bogotá: Universidad de los Andes.

Rodríguez, C., E Rodríguez, D. (2010). Cortes y cambio social. Cómo la Corte Constitucional transformó el desplazamiento forzado en Colombia. Bogotá: Dejusticia. Rodríguez, C., Alfonso, T., E Cavelier, I. (2009). El desplazamiento afro. Tierra, violencia y derechos de las comunidades negras en Colombia. Bogotá: Ediciones Uniandes. Saavedra, R. (2005). La responsabilidad extracontractual de la administración pública. Bogotá: Ediciones Gustavo Ibáñez.

Sepúlveda, J. (2002). Responsabilidad del Estado por el desplazamiento forzado (Tesis de grado para optar por el título de Especialista en Instituciones JurídicoProcesales, Universidad Nacional de Colombia, Bogotá, Colombia).

Suárez, D. (2010). Las consecuencias morales del desplazamiento: una demanda por la reconstrucción del 'proyecto de vida'. En D. Meertens, E C. Churuca, Desplazamiento en Colombia. Prevenir, asistir, transformar. Cooperación internacional e iniciativas locales (pp. 277-304). Medellín: La Carreta Editores.

Uprimny, R. (2004). Aclaración de voto a la Sentencia T-654/04. Bogotá: Corte Constitucional.

Uprimny, R., E Saffón, M. P. (2009). Reparaciones transformadoras. Justicia distributiva y profundización democrática. En C. Díaz, C. Sánchez, E R. Uprimny, Reparar en Colombia. Los dilemas en contextos de conflicto, pobreza y exclusión (pp. 31-71). Bogotá: Dejusticia.

Uprimny, R., E Saffón, M. P. (2010). Distributive justice and the restitution of dispossessed land in Colombia. En M. Bregsmo, C. Rodríguez, E M. P. Saffón, Distributive justice in transitions (pp. 379-420). Oslo: Torkel Opsahl Academic E Publisher and Peace Research Institute.

Uprimny, R., E Sánchez, C. (2010). Propuestas para una restitución de tierras transformadora. En C. Díaz, Tareas pendientes: propuestas para la formulación de politicas públicas de reparación en Colombia (pp. 193-269). Bogotá: Centro Interamericano para la Justicia Transicional.

Uprimny, R., Sánchez, N. C., E Bolívar, A. (2010). Concepto jurídico en el proceso T-24060 AC. Respuesta a Oficio UPT-A-460/2010. Recuperado de http://www. dejusticia.org/index.php?modo=internaEtema=justicia_transicionalElitigio=36 Uribe, M. T. (2001). Desplazamiento forzado en Antioquia 1985-1998. Volumen 0: Aproximaciones teóricas. Bogotá: Secretariado Seccional de Pastoral Social Sección de Movilidad-Universidad de Antioquia.

Vidal, R. C. (2007). Derecho global y desplazamiento interno. Creación, uso y desaparición del desplazamiento forzado por la violencia en el derecho contemporáneo. Bogotá: Pontificia Universidad Javeriana. 
Zanoni, E. (1984). La obligación (concepto, contenido y objeto de la relación jurídica obligatoria). Buenos Aires: San Isidro-Pcía. de Buenos Aires.

\section{Jurisprudenciales}

Colombia, Corte Constitucional. Auto 8 de 2009.

Colombia, Corte Constitucional. Auto 219 de 2011.

Colombia, Consejo de Estado, Sección Tercera. Caso La Gabarra. Radicación 25000-23-26-000-2001-00213-01 (AG) (26 enero 2006).

Colombia, Consejo de Estado. Caso Alto Naya. Radicación 190012331000200300385-01 (15 agosto 2007).

Colombia, Consejo de Estado, Sección Tercera. Caso Filogringo. Radicación 2500023-27-000-2002-00004-01 (AG) (15 agosto 2007).

Colombia, Consejo de Estado, Sección Tercera. Caso Bellacruz. Expediente 18.436 (18 febrero 2010).

Colombia, Consejo de Estado, Sección Tercera. Glueimar Echeverry y otros vs. Instituto de Seguros Sociales. Expediente 18364 (C. P. Enrique Gil Botero, 19 agosto 2009).

Colombia, Consejo de Estado, Sección Tercera. María Delfa Castañeda y otros vs. Nación-Policía Nacional. Expediente 16996 (C. P. Enrique Gil Botero, 20 febrero 2008).

Colombia, Consejo de Estado, Sección Tercera. Noelia Ospina vs. Antioquia. Expediente 22163 (28 mayo 2012).

Colombia, Corte Constitucional. Sentencia SU-1023 de 2001.

Colombia, Corte Constitucional. Sentencia T-025 de 2004.

Colombia, Corte Constitucional. Sentencia C-370 de 2006.

Colombia, Corte Constitucional. Sentencia C-715 de 2012.

Colombia, Corte Constitucional. Sentencia C-099 de 2013.

Colombia, Corte Constitucional. Sentencia C-462 de 2013 (17 julio 2013).

Colombia, Corte Constitucional. Sentencia C-912 de 2013 (3 diciembre 2013).

\section{Normativas}

Comisión de Derechos Humanos. (2005). Informe de Diane Orentlicher, experta independiente encargada de actualizar el conjunto de principios para la lucha contra la impunidad. Documento E/CN.4/2005/102. Recuperado de http://www.de- 
rechoshumanos.net/normativa/normas/onu/lesahumanidad/2005-Principiosactualizados-lucha-contra-impunidad.pdf

Colombia, Congreso de la República. Ley 387 de 1997, "por la cual se adoptan medidas para la prevención del desplazamiento forzado; la atención, protección, consolidación y estabilización socioeconómica de los desplazados internos por la violencia en la República de Colombia" (18 julio 1997).

Colombia, Congreso de la República. Ley 472 de 1998, "por la cual se desarrolla el artículo 88 de la Constitución Política de Colombia en relación con el ejercicio de las acciones populares y de grupo y se dictan otras disposiciones" (1998).

Colombia, Congreso de la República. Ley 1190 de 2008, "por medio de la cual el Congreso de la República de Colombia declara el 2008 como el año de la promoción de los derechos de las personas desplazadas por la violencia y se dictan otras disposiciones" (30 abril 2008).

Colombia, Congreso de la República. Ley 1448 de 2011, "por la cual se dictan medidas de atención, asistencia y reparación integral a las víctimas del conflicto armado interno y se dictan otras disposiciones" (9 junio 2011).

Colombia. Decreto 2569 de 2000, "por el cual se reglamenta parcialmente la Ley 387 de 1997 y se dictan otras disposiciones".

Convención de La Haya. (octubre, 1097). Convención Relativa a las Leyes y Costumbres de la Guerra Terrestre. Recuperada de http://www.icrc.org/spa/ resources/documents/misc/treaty-1907-hague-convention-4-5tdm34.htm

Organización de Estados Americanos. (noviembre, 1969). Convención Americana de Derechos Humanos. Pacto de San José de Costa Rica.

Organización de las Naciones Unidas, Asamblea General. Resolución 60/147. Principios y directrices básicos sobre el derecho de las víctimas de violaciones manifiestas de las normas internacionales de derechos humanos y de violaciones graves de derecho internacional humanitario a interponer recursos ( 21 marzo 2006). Recuperada de http://cms.onic.org.co/wp- content/uploads/ downloads/2012/03/Principios_y_directrices_basicos_sobre_reparacion.pdf Organización de las Naciones Unidas, Comisión de Derechos Humanos. (2005). Documento E/CN.4/2005/102. Recuperado de http://www.derechoshumanos.net/normativa/normas/onu/lesahumanidad/2005-Principios-actualizadoslucha-contra-impunidad.pdf

Organización de las Naciones Unidas, Asamblea General. Resolución 56/83. Documento A/56/PV.85 (12 diciembre 2001). Recuperada de http://www. un.org/Depts/dhl/spanish/resdecls/res56_1s.htm 


\title{
Instrumentos de recolección y análisis de datos
}

\author{
Tabla 1. Aplicación de la escala de fuga al caso Alto Naya
}

\begin{tabular}{|c|c|c|}
\hline Líneas de fuga teórica & Consideraciones y órdenes del fallo & $\begin{array}{l}\text { Puntaje } \\
\text { asignado }\end{array}$ \\
\hline \multicolumn{3}{|c|}{ Daño } \\
\hline $\begin{array}{l}\text { Daño cultural } \\
\text { Desconocimiento y estigma } \\
\text { social de la tragedia huma- } \\
\text { nitaria y de la condición de } \\
\text { víctima. }\end{array}$ & $\begin{array}{l}\text { Valoración del daño cultural: admitieron que el despla- } \\
\text { zamiento genera el estigma social que encasilla a sus } \\
\text { víctimas en las categorías de 'guerrilleros', 'ladrones', } \\
\text { 'mendigos'... Sin embargo, fijaron el mismo monto } \\
\text { de indemnización a todos los demandantes, sin tener } \\
\text { en cuenta el particular impacto que el desarraigo } \\
\text { causó en cada víctima. }\end{array}$ & 0,0 \\
\hline \multicolumn{3}{|c|}{ Imputación } \\
\hline $\begin{array}{l}\text { Frente al día después del éxodo } \\
\text { Considerar la omisión en la } \\
\text { búsqueda de recursos (huma- } \\
\text { nos, económicos e institucio- } \\
\text { nales) para la política pública } \\
\text { de atención a la PSD, como un } \\
\text { caso de inactividad adminis- } \\
\text { trativa que dé lugar a la falla } \\
\text { del servicio, que también se } \\
\text { presume. }\end{array}$ & $\begin{array}{l}\text { Valoración de la falta de recursos suficientes para atender } \\
\text { a la población después del éxodo: el juez hizo eco del } \\
\text { llamado de atención de la Corte Constitucional } \\
\text { acerca de la sistemática violación de derechos de la } \\
\text { PSD. Recogió el argumento de responsabilidad estatal } \\
\text { contenido en la sentencia de la Corte Constitucional } \\
\text { SU-1150 de } 2000 \text { (ya que el Estado no pudo evitar el } \\
\text { despojo de ciudadanos, que se haga responsable de la } \\
\text { atención y garantía de sus derechos con posterioridad } \\
\text { al desplazamiento), pero no lo tuvo en cuenta para } \\
\text { identificar el evento dañino. }\end{array}$ & 0,0 \\
\hline \multicolumn{3}{|c|}{ Reparación } \\
\hline $\begin{array}{l}\text { Con alcance colectivo } \\
\text { Proferir órdenes de reparación } \\
\text { a la comunidad y ampliar la } \\
\text { extensión de los remedios in- } \\
\text { dividuales a los demás afec- } \\
\text { tados, aun a aquellos que no } \\
\text { demandaron. }\end{array}$ & $\begin{array}{l}\text { Para brindar reparación con alcance colectivo: el juez } \\
\text { inaplicó algunos apartes del artículo } 55 \text { de la Ley } \\
472 \text { de } 1998 \text { para permitir que las víctimas que no } \\
\text { demandaron pudieran beneficiarse de la indemniza- } \\
\text { ción. Aun en aquellos casos en los que sus recursos } \\
\text { individuales estuviesen caducados. }\end{array}$ & 1 \\
\hline $\begin{array}{l}\text { Con alcance simbólico } \\
\text { Decretar medidas concretas } \\
\text { de no repetición, rehabilita- } \\
\text { ción y satisfacción para sanar } \\
\text { los daños morales, a la salud y } \\
\text { a la vida de relación. }\end{array}$ & $\begin{array}{l}\text { Orden de publicación del fallo en medio de comunicación } \\
\text { de amplia circulación nacional: se profirió para dar cum- } \\
\text { plimiento al artículo } 61 \text { de la Ley } 472 \text {. Su objetivo } \\
\text { directo no es ofrecer una medida de satisfacción a las } \\
\text { víctimas, sino informar a otras para que se vinculen } \\
\text { y reclamen la indemnización que les corresponda. }\end{array}$ & 0,5 \\
\hline Puntaje total & & 1,5 \\
\hline
\end{tabular}




\begin{tabular}{|l|c|}
\hline $\begin{array}{l}\text { Consideraciones sensibles a } \\
\text { líneas de fuga teórica. }\end{array}$ & 4 \\
\hline $\begin{array}{l}\text { Consideraciones con impac- } \\
\text { to alto. }\end{array}$ & 1 \\
\hline $\begin{array}{l}\text { Consideraciones con impacto } \\
\text { medio. }\end{array}$ & 1 \\
\hline $\begin{array}{l}\text { Consideraciones con impac- } \\
\text { to bajo. }\end{array}$ & 2 \\
\hline $\begin{array}{l}\text { Índice de fuga teórica (pun- } \\
\text { taje total/18). }\end{array}$ & $\mathbf{0 , 0 8}(\mathbf{1 , 5 / 1 8 )}$ \\
\hline
\end{tabular}

Tabla 2. Escala de fuga aplicada a una decisión ideal

\begin{tabular}{|c|c|}
\hline Líneas de fuga teórica & Puntaje asignado \\
\hline \multicolumn{2}{|l|}{ Daño } \\
\hline $\begin{array}{l}\text { Daño económico } \\
\text { 1. Alteración del reparto de recursos materiales al momento de la expulsión. }\end{array}$ & 1 \\
\hline $\begin{array}{l}\text { 2. Prolongación de la distribución distorsionada de recursos con la falta de } \\
\text { atención por parte de las autoridades. }\end{array}$ & 1 \\
\hline $\begin{array}{l}\text { Daño cultural } \\
\text { 3. Desconocimiento y estigma institucional de la tragedia humanitaria y de la } \\
\text { condición de víctima. }\end{array}$ & 1 \\
\hline $\begin{array}{l}\text { 4. Desconocimiento y estigma social de la tragedia humanitaria y de la condi- } \\
\text { ción de víctima. }\end{array}$ & \\
\hline 5. Imposición de una identidad relacionada con el enemigo. & 1 \\
\hline $\begin{array}{l}\text { Daño político } \\
\text { 6. Pérdida de capacidad de interlocución con las autoridades. }\end{array}$ & 1 \\
\hline $\begin{array}{l}\text { 7. Pérdida de la capacidad de organización y asociación para superar la tragedia } \\
\text { humanitaria. }\end{array}$ & 1 \\
\hline \multicolumn{2}{|l|}{ Imputación } \\
\hline $\begin{array}{l}\text { Frente al éxodo } \\
\text { 8. Presunción de falla del servicio en la ocurrencia del éxodo. }\end{array}$ & 1 \\
\hline $\begin{array}{l}\text { Frente al día después del éxodo } \\
\text { 9. Considerar la omisión en la búsqueda de recursos (humanos, económicos } \\
\text { e institucionales) para la política pública de atención a la PSD, como un caso } \\
\text { de inactividad administrativa que dé lugar a la falla del servicio, que también } \\
\text { se presume. }\end{array}$ & 1 \\
\hline
\end{tabular}




\begin{tabular}{|l|c|}
\hline \multicolumn{1}{|c|}{ Líneas de fuga teórica } & Puntaje asignado \\
\hline \multicolumn{1}{|c|}{ Reparación } \\
\hline $\begin{array}{l}\text { Para corregir el desajuste temporal } \\
\text { 10. Dar trámite preferente a las demandas de reparación de la PSD, sea en el } \\
\text { curso de una acción de grupo o de la reparación directa. }\end{array}$ & 1 \\
\hline $\begin{array}{l}\text { 11. Ampliar de oficio el alcance del problema jurídico por debatir. Evaluar la } \\
\text { existencia de daños, su imputación y reparación frente a dos eventos: el } \\
\text { éxodo y el día después. }\end{array}$ & 1 \\
\hline $\begin{array}{l}\text { Con alcance colectivo } \\
\text { 12. Proferir órdenes de reparación a la comunidad y ampliar la extensión de } \\
\text { los remedios individuales a los demás afectados, aun a aquellos que no } \\
\text { demandaron. }\end{array}$ & 1 \\
\hline $\begin{array}{l}\text { Con alcance simbólico } \\
\text { 13. Decretar medidas concretas de no repetición, rehabilitación y satisfacción } \\
\text { para sanar los daños morales, a la salud y a la vida de relación. }\end{array}$ & 1 \\
\hline $\begin{array}{l}\text { 14. Enfocar la indemnización hacia el cubrimiento exclusivo de daños materiales } \\
\text { (emergente y lucrocesante). }\end{array}$ & 1 \\
\hline $\begin{array}{l}\text { Con alcance participativo } \\
\text { 15. Indicar el sentido del fallo y antes de proferirlo convocar a audiencia pública } \\
\text { de discusión, para que las partes expongan sus argumentos sobre los límites } \\
\text { y formas de reparación (alto participativo en el camino). }\end{array}$ & 1 \\
\hline $\begin{array}{l}\text { Con enfoque diferencial } \\
\text { 16. La sentencia debería tener en cuenta las condiciones de vulnerabilidad } \\
\text { previas al despojo, y no solamente la magnitud del daño. }\end{array}$ & 1 \\
\hline $\begin{array}{l}\text { 17. Ajustar la base de liquidación del perjuicio lucrocesante en aquellos casos } \\
\text { en los que no se logra probar un ingreso de la víctima superior al salario } \\
\text { mínimo. }\end{array}$ & 1 \\
\hline $\begin{array}{l}\text { Con alcance regional } \\
\text { 18. Orrdenes concretas de reparación que comprometan a los departamentos } \\
\text { marco de sus competencias. }\end{array}$ & 1 \\
\hline
\end{tabular}

